\title{
Temporal Trend Analysis of Climatic Parameters of Savitri Basin
}

\author{
K.D. Gharde ${ }^{*}$, M.B. Nagdeve and Y. Bisen \\ Department of Soil and Water Conservation Engineering, Dr. PDKV, Akola, India
}

*Corresponding author

\begin{abstract}
A B S T R A C T
The climatic parameters such as Rainfall, mean daily temperature, Wind Speed, relative humidity are spatial and changing with time space and position. That directly affects the availability of basic

Keywords

Stationarity, Seasonality, Auto correlation function, Hydrologic models

Article Info

Accepted:

12 July 2019

Available Online:

10 August 2019 resources such as surface runoff, vegetation, soil health and quality needed for betterment of sustainability of human being. The predicting the surface runoff is complex and uncertain. It depended of these climatic parameters. Hence, their behaviour needed to be understood before putting in the hydrologic model. In present study the trend of the climatic parameter were estimated by non-parametric Mann Kendal test, seasonality tested with Dickey Fuller stationary test and Stationarity with KPSS test. The validity of inputs parameter to adopt was tested with cross correlation of the input data sets. The data such as Rainfall, Mean daily temperature, Surface runoff and daily evaporation considered of 12 stations nearby the Savitri Basin for duration of 1992 to 2011 (20 years). It is revealed that, the rainfall and surface runoff is with stationary without any trends whereas temperature and evaporation showed non stationary with increasing trends for duration of 1992 to 2011 for Savitri Basin. The ACF and PACF gives with seasonal differencing (120 days) observed sinusoidal wave patter with changing season's effect on the ACF and PACF coefficient. The maximum cross correlation between rainfall and runoff of Savitri basin were exists at less lag i.e at one day, whereas it goes continuously deceasing with increase in the lag day up to 7 days. It is implies that, It is necessary to check the consistency of data sets used for hydrologic model before putting in the models.
\end{abstract}

\section{Introduction}

The statistical hydrology plays an important role in time series analysis, drought monitoring and estimation, flood risk estimation and surface runoff modelling, etc. The statistical domain of hydrology has broadened to encompass the problems of both surface and groundwater systems. The Statistics is being acknowledged as powerful tool in analysing the time series in hydrology. This time series analysis are used for described or detects the changes in trends or pattern in sequence with time from given observations [1] (Machiwal and Jha, 2006). The hydrologic time such as rainfall, temperature (Max or Min), evaporation etc) are used to developed mathematical models to forecast the hydrologic events, to identify the changes in trends or shift in hydrologic records, and fill the missing recorded dada and to extends the dada [2] (Salas, 1993). The hydrological time serried data used for rainfall runoff and sediment modelling assuming the series is homogenous, stationary, free from trends and shifts, non-periodic with no 
persistence [3] (Adeloye and Montaseri, 2002). Homogeneity means the series belongs one population and have a time invariant mean whereas non homogeneity caused due to methods of data collection or environment in which it is done [4] (Fernando and Jayawardena, 1994). Stationarity means the statistical parameters of the series computed from different samples do not change except due to sampling variations. A time series is said to be strictly stationary if its statistical properties do not vary with changes of time origin.

A hydrological time series may occur to abrupt changes or gradual trends or may take more complex form. A hydrologic time series is said to be have trends when there is significant correlation between the recorded data with respect to tome. Trends and shifts in hydrologic time series are usually introduced due to artificial or natural changes. The natural changes are gradual occurs due the regional or global climatic changes. The artificial change is usually noted in the overall record at a monitoring site, but this information is not always presented with the sites' data series. The variables (rainfall, temperature, evaporation streamflow or sediment yield) appear to have a trend may actually just represent a change in climatological conditions near the monitoring site [5] (Hameed et al., 1997). To test hydrological models' capability to predict climate change impacts on hydrology there is a need for long time series showing climate change. However, it might be problematic to differentiate between the effects of climate change and the impact of direct anthropogenic undertakings such as river regulations, water abstractions, irrigation, fertilization, etc. The influence of these changes should therefore be considered with care when trying to disassemble the climate change impact signal. The used of hydrological models for prediction of runoff and sediment yield from precipitation and meteorological data were different from the period where they are calibrated and results in reduced performance [6, 7, 8] (DonnellyMakowecki and Moore, 1999; Refsgaard and Knudsen, 1996; Seibert, 2003). Karlsson, et al., (2014) [9] analysed the rends of precipitation and streamflow using Mann Kendal test. Mohammad et al., (2014) [10] assesses the relation between rainfall and streamflow based on the statistical parameters and found that rainfall lag by one to two days found responding well for streamflow modelling.

The present study was undertaken to study the statistical response of hydrologic time series to generate streamflow from rainfall. In statistical term we determine the trends of rainfall, temperature, evaporation streamflow its seasonality and stationarity. In present study, Mann Kendal Test is used to determine the trends in climatic and hydrologic data series, because, it is non-parametric test and underlying very less assumptions about the structures of the data [11] (Helsel and Hirsch, 1988). Autocorrelation and partial correlation between the data sets were determined to identify the best model and pattern of the data structures. The cross correlation between the rainfall and streamflow were determined to identified the lag of data to be used for input in modelling the runoff by hydrologic models.

\section{Materials and Methods}

\section{Study area and data used}

The present study was conducted for the Savitri river basin comes under the Western part of Sahayandri Ghat of Konkan region and located in Maharshtra State of India (Fig. 1). The location of study is given in Figure 1. The latitude is ranges from $18^{0} 20^{\prime} \mathrm{N}$ to $17^{0} 51^{\prime} \mathrm{N}$ and longitude ranges from 73022 " $\mathrm{E}$ to 73041 'E with mean elevation from Sea surface is $6.50 \mathrm{~m}$ to $1366.22 \mathrm{Km}$. Each has 
hydrological and meteorological gauging stations located at Koturde, Birwadi, Kangule and Bhave at their outlets point and at Mahad for Savitri basin. The average rainfall, runoff, evaporation and temperature were taken for modelled daily runoff for duration of 20 years (1992 to 2011) of all stations is presented in Table 1.

Trends analysis, seasonality and
stationarity test

\section{Mann-Kendall test}

The trend of hydrologic time series was analysed using non-parametric Mann- Kendall test. Which is statistical method used for identify the spatial variation and temporal trends in climatic parameters time series.

A non-parametric test is taken into consideration over the parametric one since; it can evade the problem reused by data skew. The Mann Kendall Test statistics is given by following equation.

$$
S=\sum_{t=1}^{n-1} \sum_{j=t+1}^{n}\left(\operatorname{sgn}\left(x_{j}-x_{i}\right)\right)
$$

The application of trend test is done to a time series $x_{i}$ that is ranked from $i=1,2, \ldots \ldots \ldots n-1$ and $x_{j}$, which is ranked from $j=$ $\mathrm{i}+1,2, \ldots \ldots \ldots . . . \mathrm{n}$.

$$
Z_{c}=\left\{\begin{array}{c}
(S-1) / \sqrt{\operatorname{Var}(S)} \\
0, S=0 \\
(S-1) / \sqrt{\operatorname{Var}(S)}, S=0
\end{array}\right.
$$

Where,

$Z_{e}=$ Trends in Data sets, if the value of $Z_{e}$ is positive or negative mean trends is upward or downwards trend.

\section{Stationary test}

Stattionarity of input data sets in climatic parameter can check by using Dickey and fuller test proposed by Dickey and fuller (1979) [12]. This is express by Model as.

$Y_{t}=\alpha+y_{t-1}+u_{t} \ldots .3$

Where,

$\mathrm{y}_{\mathrm{t}}=$ stationarity parameters which independent and identical.

$\mathrm{u}_{\mathrm{t}}=$ an independent and identically distributed zero mean error.

$\alpha=0$ (Is random wald without walk)

The Dickey and fuller model is fitted and modified as

$y_{t}=\alpha+p y_{t-1}+\delta_{t}+u_{t} \ldots 4$

Where $\alpha=0$ and $\delta=0$ considering by least square test and this regression test is performed by null hypothesis using t-test which $\mathrm{H}_{0}: \beta=0$ does not have standard distribution.

\section{Kwiatkowski-Phillips-Schmidt-Shin (KPSS) stionarity test}

The alternative test introduced in 1992 by Kwiatkowski, Phillips, Schmidt and Shin, and called henceforth the KPSS test [13] (Syczewska, 1997) has a null of stationarity of a series around either mean or a linear trend; and the alternative assumes that a series is non-stationary due to presence of a unit root. In this respect, it is innovative in comparison with earlier Dickey-Fuller test, or Peron type tests, in which null hypothesis assumes presence of a unit root which is described as following. 
$y_{t}=\zeta_{t}+r_{t}+\varepsilon_{t} \ldots \ldots \delta \ldots .5$

$\mathrm{y}_{\mathrm{t}}=$ Observed time series variables with deterministic trends $(\mathrm{t})$

$\mathrm{r}_{\mathrm{t}}=$ random variables

$\varepsilon_{\mathrm{t}}=$ error with assumption that series is stationary

By assumption, an initial value of the second equation in (Eq. 5) is a constant; and it corresponds to an intercept. The null hypothesis of stationarity is equivalent to the assumption that the variance $\sigma^{2}$ of the random walk process $r_{t}$ in equation (Eq. 5), equals zero. In case when $\xi=0$, the null means that is $\mathrm{y}_{\mathrm{t}}$ is stationary around $\mathrm{r}_{0}$. If $\xi \neq 0$, then the null means that $y_{t}$ is stationary around a linear trend. If the variance $\sigma^{2}$ is greater than zero, then $\mathrm{y}_{\mathrm{t}}$ is non-stationary (as sum of a trend and random walk), due to presence of a unit root.

Subtracting $\mathrm{y}_{\mathrm{t}}$ from both sides of the first equation in equation (Eq. 6) we obtain:

$\Delta \mathrm{y}_{\mathrm{t}}=\xi_{\mathrm{t}}+\mathrm{u}_{\mathrm{t}}+\Delta \varepsilon_{\mathrm{t}}=\xi+\mathrm{w}_{\mathrm{t}} \ldots 6$

Where, $\mathrm{w}_{\mathrm{t}}$ to assumption that $\varepsilon_{\mathrm{t}}$, and $\mathrm{u}_{\mathrm{t}}$, are independently identically distributed random variables, is generated by an autoregressive process AR(1) [14](Kwiatkowski et al., 1992): $\mathrm{w}_{\mathrm{t}}=\mathrm{v}_{\mathrm{t}}+\theta \mathrm{v}_{\mathrm{t}-1}$. Hence the KPSS model may be expressed in the following form:

$\mathrm{yt}=\xi+\beta \mathrm{y}_{\mathrm{t}-1}+\mathrm{w}_{\mathrm{t}} \ldots 7$

$\mathrm{wt}=\mathrm{v}_{\mathrm{t}}+\mathrm{v}_{\mathrm{t}-1}, \beta=1 \ldots 8$

This Eq. 7 and Eq.8 expresses an interesting relationship between KPSS test and DF test, as DF test checks $\beta=1$ on assumption that $\theta=0$; where $\theta$ is a nuisance parameter. Kwiatkowski et al., assume that $\beta$ is a nuisance parameter, and test whether $\theta=-1$, assuming that $\beta=0$. They introduced one side e Lagrange Multiplier test of null hypothesis $\sigma^{2}{ }_{u}=0$ with assumption that $\mathrm{u}_{\mathrm{t}}$ have a normal distribution and $\varepsilon_{\mathrm{t}}$ are identically distributed independent random variables with zero expected value and a constant variance $\sigma_{u \text { u. }}^{2}$

\section{Autocorrelation function (ACF)}

The autocorrelation function measures the correlation of a signal $\mathrm{X}(\mathrm{t})$ with itself shifted by some time delay $\tau$ :

$C(\tau)=\frac{1}{t-\tau} \int_{n-m-1}^{t-\tau} x(t) x(t+\tau) d t$

Eq. 10 can be rewritten as for large period with degree of freedom m-1as follows

$C(m)=\frac{1}{N-m} \sum_{n=0}^{n-m-1} x(m) x(n+m)$ $\ldots 10$

Where,

$\mathrm{C}(\tau)=$ autocorrelation function with delay time $\mathrm{t}$,

$\mathrm{C}(\mathrm{m})=$ autocorrelation function with lag period by degree of freedom $m$

$\mathrm{N}=$ number of sample

$\mathrm{m}=$ degree of freedom for lag time $\mathrm{t}$

The period of the auto-correlation correspond to the period of the signal. In presence of noise, envelop of the auto-correlation function decreases exponentially. This phenomenon is also called "phase diffusion".

\section{Partial autocorrelation function (PACF)}

The partial autocorrelation function (PACF) is an important toll to analyse the extents of lags in an autocorrelation model. The approached of this time series model to determine appropriates lags $\mathrm{p}$ in a time series $\mathrm{Zt}$ by 
plotting the partial autocorrelation function and its is denoted by lak or $\alpha(\mathrm{k})$. This mean the autocorrelation between $\mathrm{Zt}$ and $\mathrm{Zt}+\mathrm{k}$ which is not accounted for by lags 1 to $\mathrm{k}-1$ inclusive. This is stated as follows:

$\alpha(1)=\operatorname{Cor}\left(z_{t}, z_{t+1}\right) \ldots 11$

$\alpha(1)=\operatorname{Cor}\left(z_{t+k}-P_{t, k}\left(z_{t+1}\right), z_{t}-P_{t, k}\left(Z_{t}\right)\right)$, fork $\geq 2$ ....12

Where,

$\mathrm{P}_{\mathrm{t}, \mathrm{k}}(\mathrm{x})=$ denotes the projection of $\mathrm{x}$ onto the spaced spanned by $Z_{t+1}, \ldots \ldots, Z_{t+k-1}$

$\alpha(\mathrm{t})=$ PACF lag by $\mathrm{t}$

$\alpha(k)=$ PACF lag by $k$

This generally PACF plot adopted for identify the order of an autoregressive model. The $\mathrm{PACF}$ is zero at lag $\mathrm{P}+1$ and greater.

\section{Cross correlation function (CCF)}

The cross correlation is a measures of similarity of input time series as a function of time lag applied to one of them. This generally applied for a long signal for a shorter known feature. For continuous functions $f$ and g. This is defined as:

$$
(f x g)(\tau) \frac{d e f}{\equiv} \int_{-\infty}^{\infty} f(t) g[t+\tau] d t \quad \ldots 13
$$

Where, $\mathrm{f}^{*}=$ complex conjugate of $\mathrm{f}$ $\tau=$ time lag

\section{Results and Discussion}

\section{Statistical Parameters of Input Data}

Time series technique applied in this research consists of estimation of trend components
(Mann Kendall test) [15] (Brockwell and Davis, 2002), seasonality (Dickey and Fuller test) and stationarity (KPSS test), autocorrelation function (ACF), partial autocorrelation function (PACF), cross correlation function $(\mathrm{CCF})$. To undertake a robust statistical technique for analyzing the hydrologic data, which relates to time series such as rainfall, runoff, temperature, and evaporation have been employed.

The statistical parameters such as mean, maximum, minimum, SD, SE, mean ACF, mean PACF) of hydrologic time series data for 20 years (1992 to 2011) of Savitri basin of Konkan region in Maharashtra of rainfall, runoff, temperature and evaporation estimated and are presented in Table 1. The number of sampled were analysed for duration of 20 years were 2483. The maximum rainfall, runoff, temperature and evaporation was 366.9 $\mathrm{mm}, 4932.34$ cumecs, $40.30{ }^{\circ} \mathrm{C}$ and $16 \mathrm{~mm}$ respectively whereas minimum was $0.0 \mathrm{~mm}$, 0.01 cumecs, $23.9^{\circ} \mathrm{C}$ and $0.2 \mathrm{~mm}$, respectively. The standard deviation observed for rainfall, runoff, temperature, evaporation was 36.56, 532.31, 1.25 and 2.44, respectively. The minimum SD observed for evaporation and Temperature and the minimum standard error (SE) was for runoff and same found to rest of the hydrologic time series. The least mean ACF (0.0093) was for rainfall followed by runoff (0.0146), evaporation (0.106) and maximum mean ACF was of temperature (0.1715). The least PACF of runoff (0.0045) and highest for temperature and evaporation (0.0166) followed by rainfall $(0.0145)$.

\section{Trends and Stationarity Analysis of Input Data Sets}

Analysed trends in hydrologic time series such as rainfall, runoff, temperature and evaporation for Savitri basin by Mann-Kendall test. The stationary and seasonality of hydrologic data were analysed by Dickey 
Fuller test and KPSS test respectively. The results of Mann Kendall test, Dickey Fuller test and KPSS test are presented in Table 2. The trends of hydrologic data used by moving average method are presented in Figure 2 (ad). The Tau value for rainfall, runoff, temperature and evaporation time series by Maan Kendall test was 0.01, 0.012, -0.026 and -0.194 respectively. The positive value indicates the increasing trends whereas the negative value indicating decreasing trends. The value of tau (t) for rainfall and runoff positive but indicates the constant fluctuating the rainfall and runoff about it mean value over the period of study. The moving average trends were also plotted and it was observed that, rainfall and runoff series are constant and fluctuating with it mean value (Fig. $2 \mathrm{a}$ and $2 b$ ). whereas the temperature and evaporation is decrease with increase the time period, the same trends is observed from the Figure 2(c) and Figure 2(d) for temperature and evaporation. Hence temperature and evaporation is lesser in recent day compared to the starting of 1992 to 2005 . But these not affect on the runoff and rainfall patter of the study area.

It is observed from the Table 2 that, the computed alpha value is less than 0.05 in case of rainfall, runoff, temperature and evaporation for Savitri basin. Same results were also found in case of Dickey Fuller and KPSS test. It interfered that the data used for modelling runoff for Savitri basin with stationarity and with no trends except temperature and evaporation. But temperature and evaporation are found nonstationary with changing decreasing trends.

\section{Autocorrelation Function (ACF)}

The autocorrelation function (ACF) is a set of correlation coefficients between the series and lags of itself over time. Stationarity is a necessary condition in building an ARIMA model that is useful for forecasting. Testing for independence (randomness) against serial dependence is a fundamental problem in time series analysis. To determine whether a time series, $x(t)$, is independent, the function (ACF) of the series is examined. If the $\mathrm{ACF}$ is significantly different from zero, this implies that there is dependence between observations. Therefore, ACF is a powerful complementary tool for testing independence $[16,17]$ (Janacek and Swift, 1993; Ferguson et al., 2000). Most common method to check stationarity in data series is examining the graph or time plot of the data and ACF is determined against different lags.

The ACF for rainfall and lag time was plotted to check the stationary. The rainfall is lag by 120 days (seasonal lag) shows the data is varied in the ACF coefficient of \pm 0.0094 . It indicates that, the rainfall is stationary with change of seasons over Savitri basin. The rainfall ACF plot is presented in Figure 3.

The runoff gauged at Mahad station, outlet of Savitri basin for duration of 1992 to 2011 (20 years), checks its stationarity by plotting ACF and Lag (Fig. 4). It is observed that, the runoff of Savitri basin is stationary with seasonal changes. The same trend was observed for the temperature (Fig. 5) and evaporation (Fig. 6). The temperature and evaporation have negative correlation and found to be decreasing trends. It not shows much seasonal variation. The same trends as discussed above were found for all data sets used i.e stationary.

\section{Partial Autocorrelation Function (PACF)}

The partial autocorrelation function (PACF) is the partial correlation coefficients between the series and lags of itself over time. The partial autocorrelation function provides a similar way of identifying a series as a purely autoregression one. The partial autocorrelations are useful in identifying the order of an autoregressive model. 
Fig.1 Location of Savitri Basin

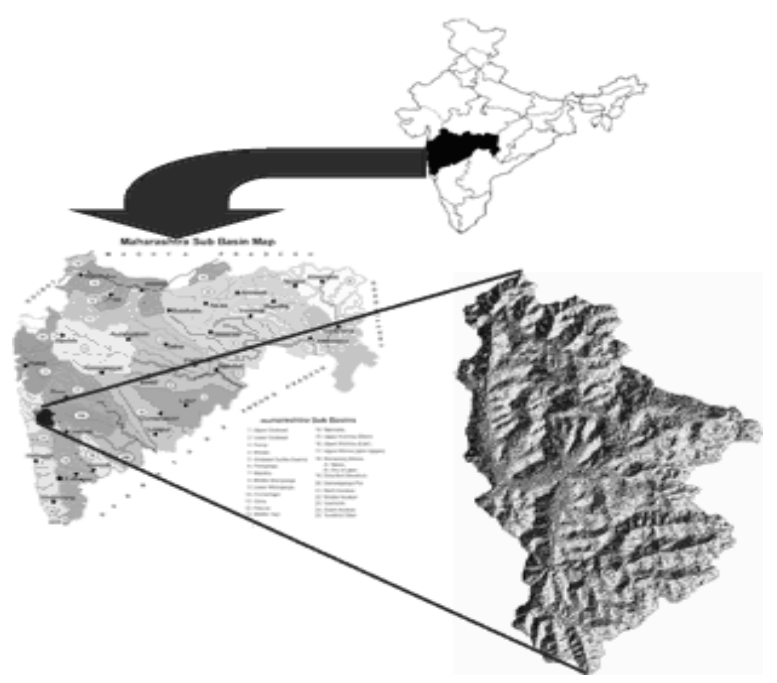

Fig.2 (a-d) Moving average trend of rainfall, runoff, temp and evaporation of Savitri basin

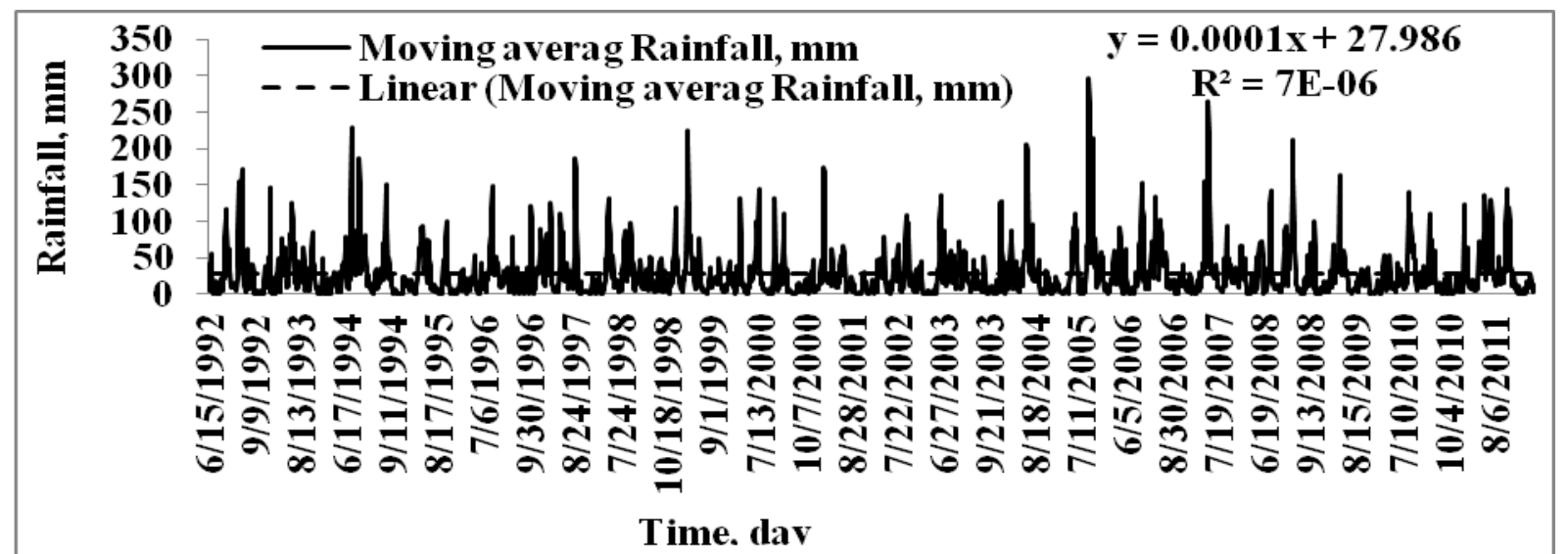

Fig.2(a) Rainfall moving average trends for Savitri Basin during 1992 to 2011 (20 years)

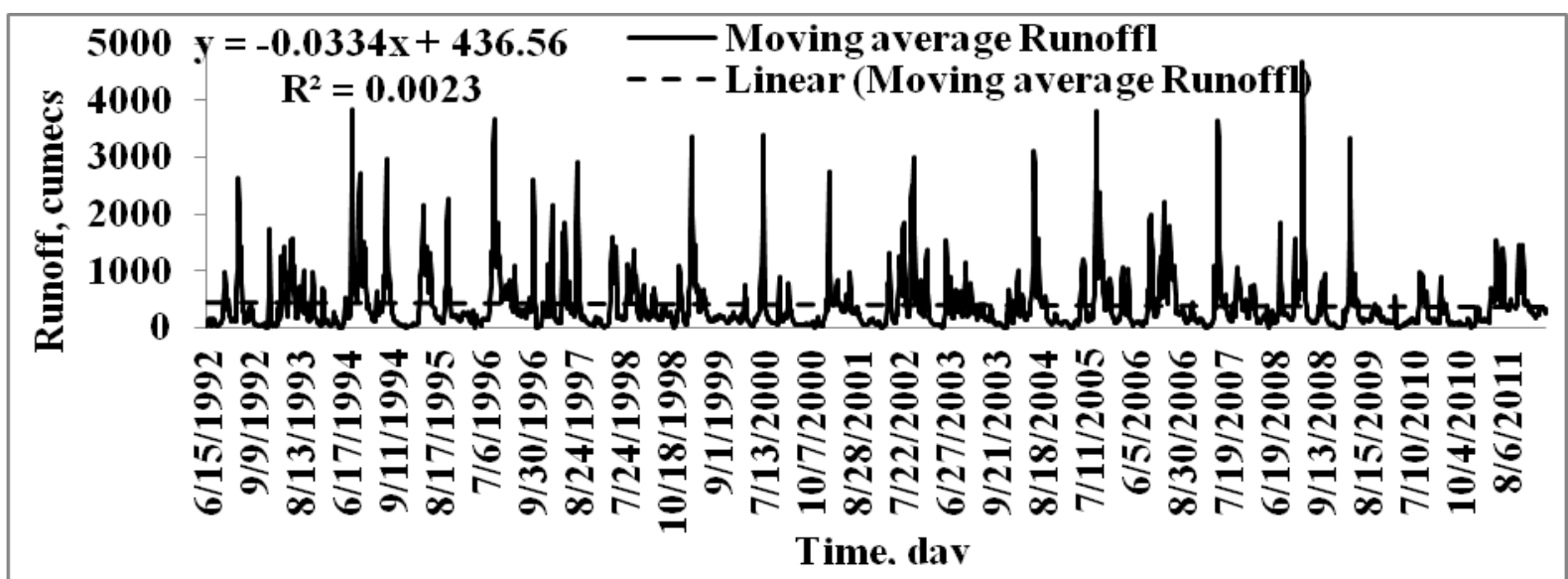

Fig.2(b) Runoff moving average trends for Savitri Basin during 1992 to 2011 (20 years) 


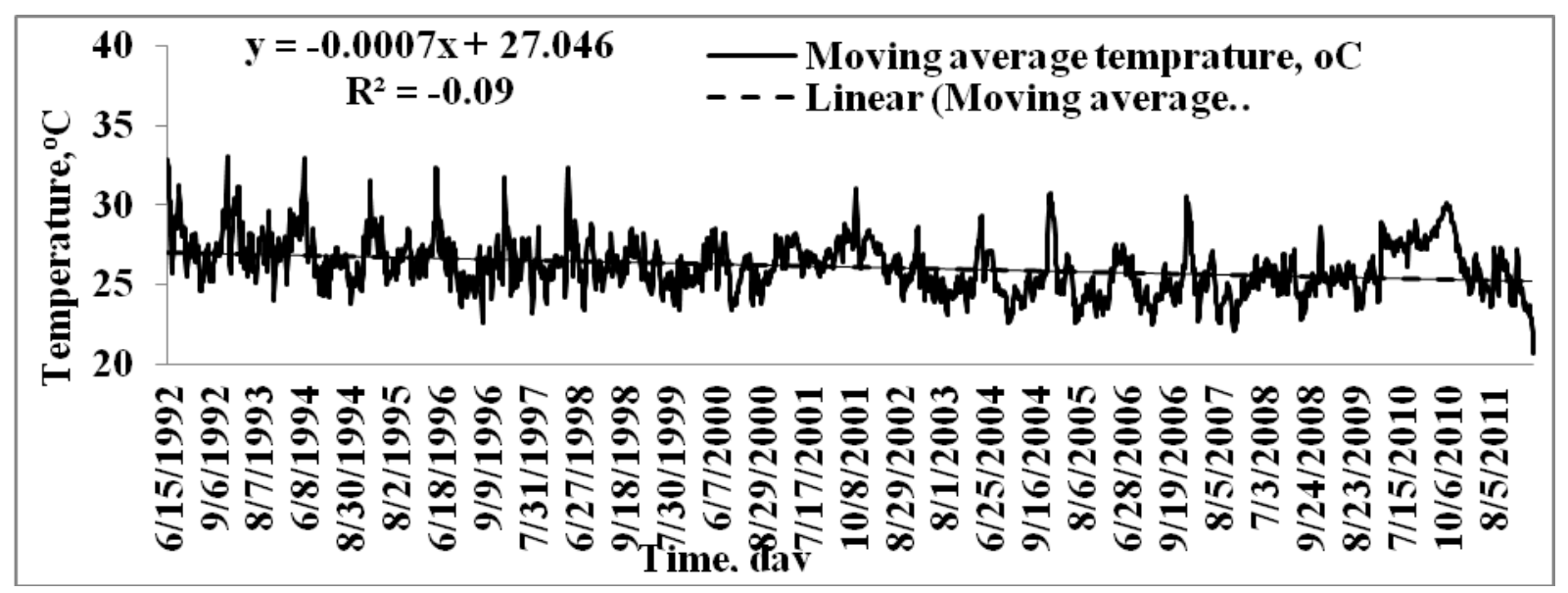

Fig.2(c) Temperature moving average trends for Savitri Basin during 1992 to 2011 (20 years)

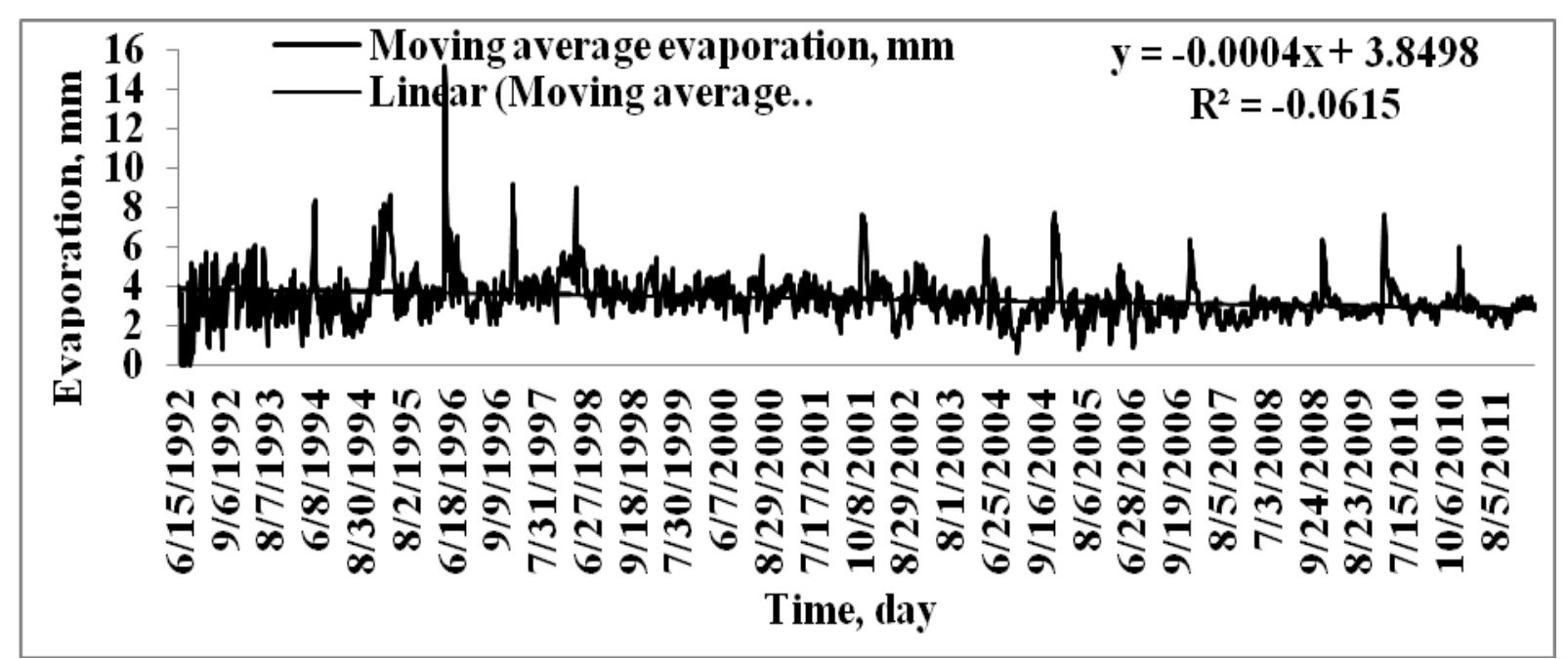

Fig.2(d) Temperature moving average trends for Savitri Basin during 1992 to 2011 (20 years)

Fig.3 Rainfall ACF of Savitri basin

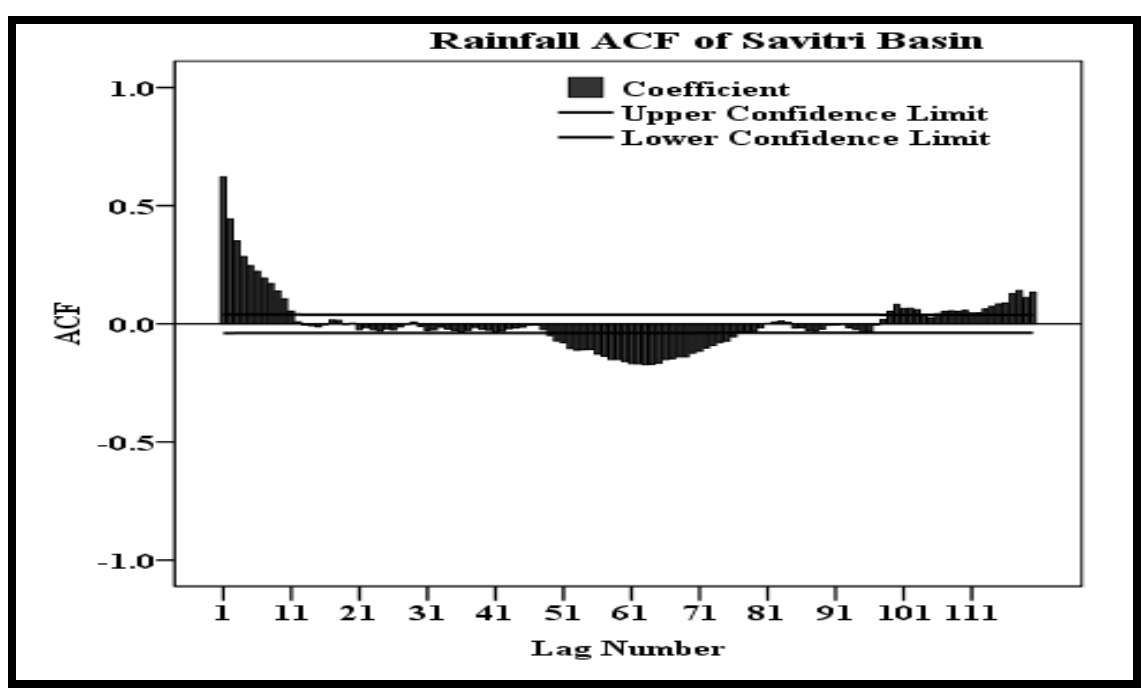


Fig.4 Runoff ACF of Savitri basin

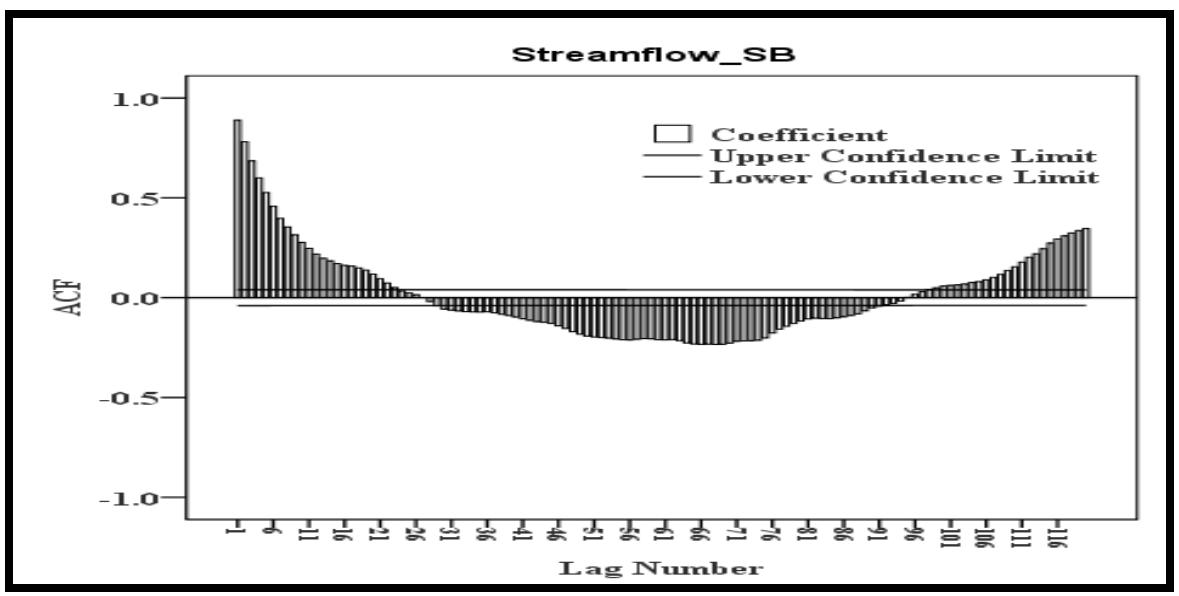

Fig.5 Temperature ACF of Savitri basin

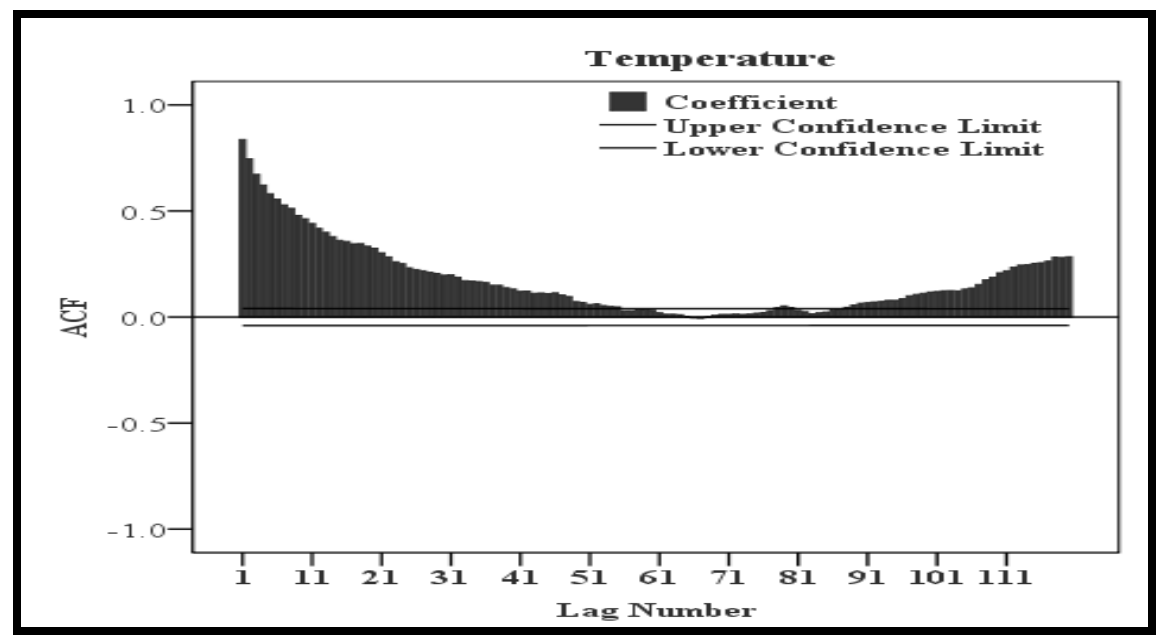

Fig.6 Evaporation ACF of Saviri basin

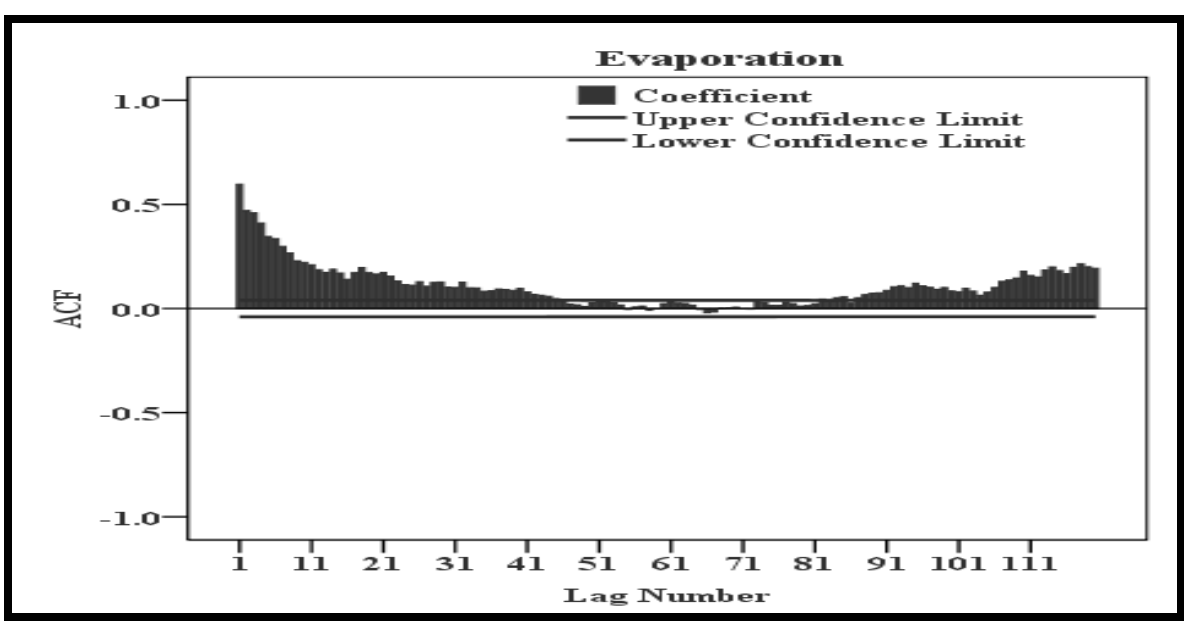


Fig.7 Rainfall PACF of Savitri basin

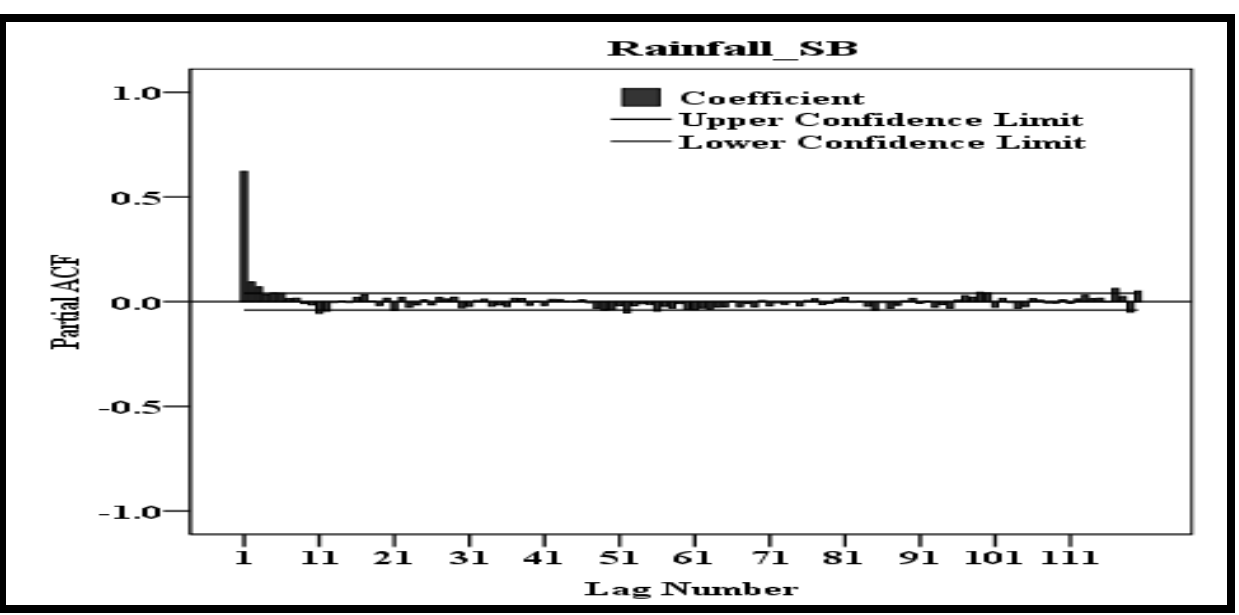

Fig.8 Runoff PACF of Savitri basin

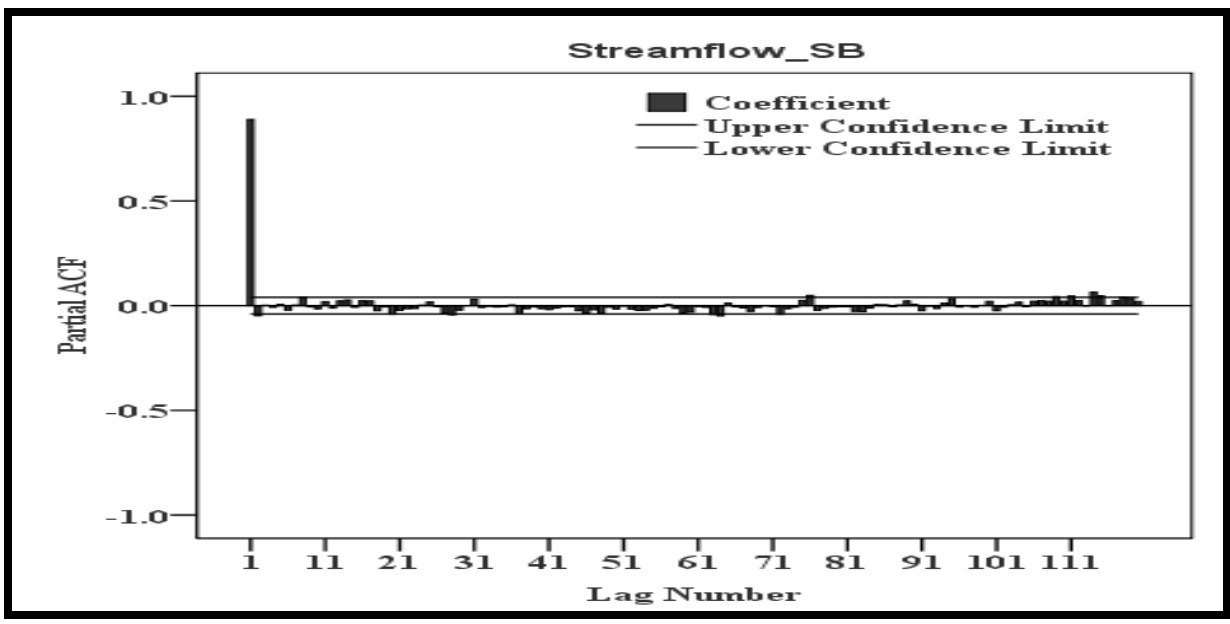

Fig.9 Temperature PACF of Savitri basin

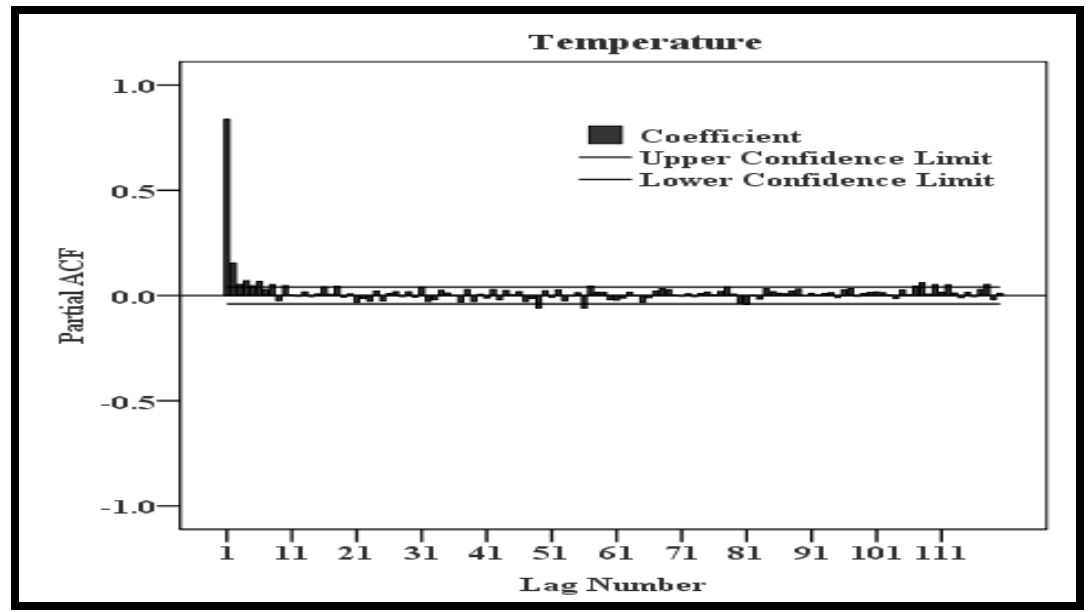


Fig.10 Evaporation PACF of Savitri basin

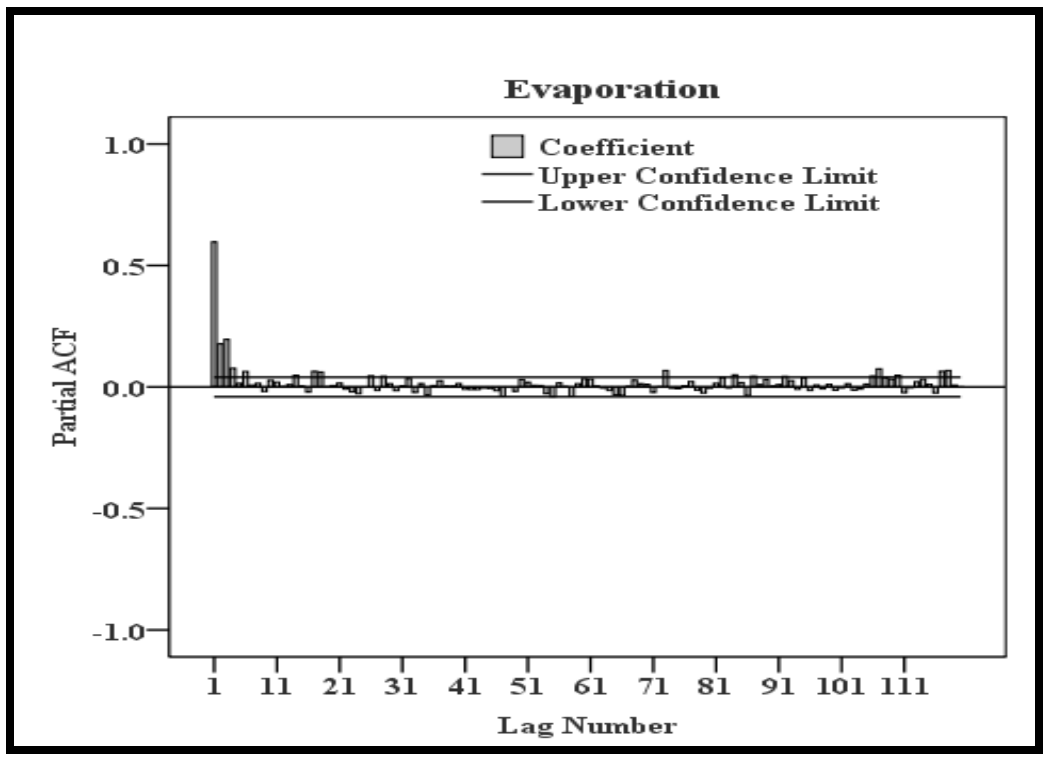

Fig.11 Cross correlation between rainfall and stream flow of Savitri basin and Kal River

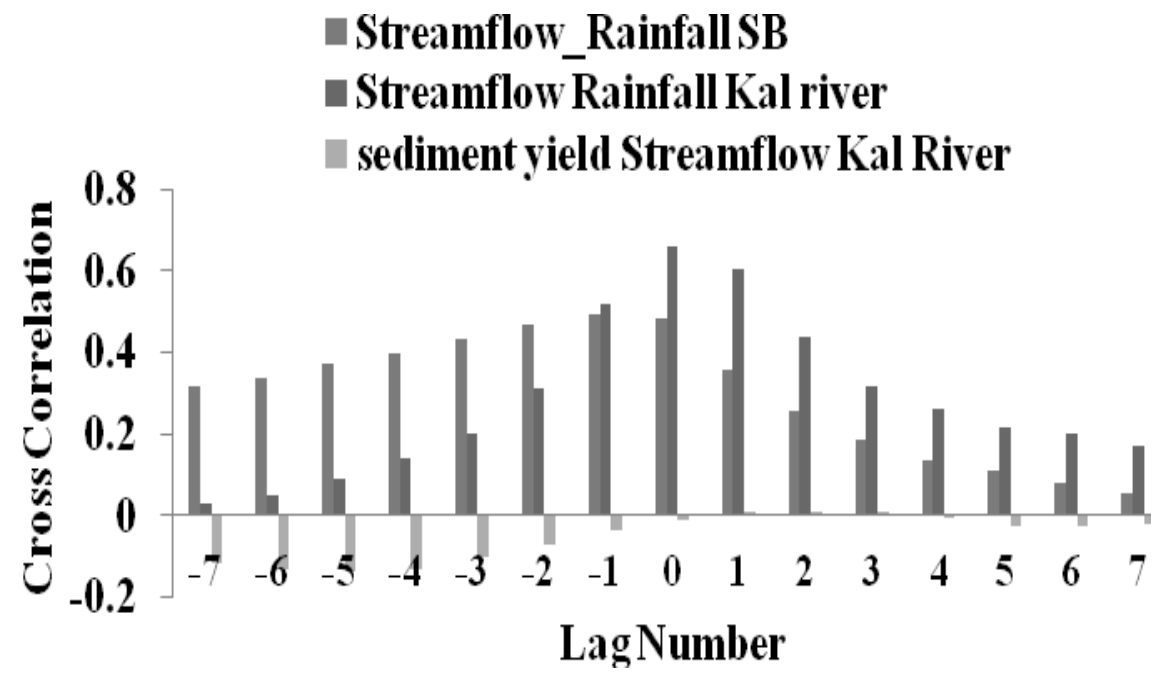

Table.1 Statistical parameters of input data sets for Svaitri basin

\begin{tabular}{|c|l|c|c|c|c|c|c|c|c|}
\hline $\begin{array}{c}\text { Sr } \\
\text { No }\end{array}$ & \multicolumn{1}{|c|}{ Data } & $\begin{array}{c}\text { No of } \\
\text { sample }\end{array}$ & Max & Min & Mean & SD & ACF & PACF & SE \\
\hline $\mathbf{1}$ & Rainfall, mm & 2483 & 366.9 & 0.1 & 28.14 & 36.56 & 0.0093 & 0.0145 & 0.020 \\
\hline $\mathbf{2}$ & Runoff,cumecs & 2383 & 4932.3 & 0.01 & 395.1 & 532.31 & 0.0146 & 0.0045 & 0.019 \\
\hline $\mathbf{3}$ & Temp, ${ }^{\circ} \mathrm{C}$ & 2383 & 40.30 & 23.9 & 29.78 & 2.44 & 0.1715 & 0.0161 & 0.020 \\
\hline $\mathbf{4}$ & $\begin{array}{l}\text { Evaporation, } \\
\text { mm }\end{array}$ & 2383 & 16 & 0.2 & 3.36 & 1.25 & 0.106 & 0.0166 & 0.020 \\
\hline
\end{tabular}


Table.2 Trends analysis of rainfall, runoff and sediment data of Savitri basin

\begin{tabular}{|c|c|c|c|c|c|c|c|c|}
\hline \multirow[t]{2}{*}{$\begin{array}{l}\text { Sr. } \\
\text { No. }\end{array}$} & \multirow[t]{2}{*}{$\begin{array}{c}\text { Hydrological } \\
\text { data }\end{array}$} & \multicolumn{2}{|c|}{$\begin{array}{c}\text { Mann Kendall } \\
\text { Test* }\end{array}$} & \multicolumn{2}{|c|}{$\begin{array}{c}\text { Dickey Fuller } \\
\text { test }^{\#}\end{array}$} & \multicolumn{2}{|c|}{ KPSS test $* *$} & \multirow[t]{2}{*}{$\begin{array}{l}\text { Interf } \\
\text { erence }\end{array}$} \\
\hline & & $\begin{array}{c}\tau \\
\text { value }\end{array}$ & $\begin{array}{c}\mathbf{P} \\
\text { value }\end{array}$ & $\begin{array}{c}\tau \\
\text { value }\end{array}$ & $\begin{array}{c}\mathbf{P} \\
\text { values }\end{array}$ & $\begin{array}{c}\tau \\
\text { value }\end{array}$ & $\begin{array}{c}\mathbf{P} \\
\text { values }\end{array}$ & \\
\hline 1 & Rainfall, mm & 0.01 & 0.682 & -11.97 & $<0.0001$ & 0.054 & 0.519 & SNT $^{\$}$ \\
\hline 2 & Runoff, cumecs & 0.012 & 0.684 & 0.05 & $<0.0001$ & -10.49 & 0.53 & SNT \\
\hline 3 & $\begin{array}{c}\text { Temperature, } \\
{ }^{\circ} \mathrm{C}\end{array}$ & -0.026 & 0.057 & -7.00 & 1.00 & 0.556 & $<0.001$ & NSDT \\
\hline 4 & $\begin{array}{c}\text { Evaporation, } \\
\text { mm }\end{array}$ & -0.194 & $<0.0001$ & -9.24 & 1.00 & 0.321 & 0.002 & NSDT \\
\hline
\end{tabular}

* Mann Kendall Test (MKT) interference: $\mathrm{H}_{0}=$ there is no trend in series, $\mathrm{H}_{\mathrm{a}}=$ there is trend in the series, As the computed alpha $(\alpha=0.05)$ is greater than $\mathrm{P}$ value, hence there is no trend in the series. Or if the computed alpha $(\alpha=0.05)$ value is less than $P$ value, hence there trend in the series.

\# Kwiatkowski-Phillips-Schmidt-Shin (KPSS) trend test interference: $\mathrm{H}_{0}$ : the series is stationary, ha: the series is not stationary, As the computed p-value is greater than the significance level alpha $=0.05$, one cannot reject the null hypothesis $\mathrm{H}_{0}$.

** Dickey Fuller test ADF (stationary) interference: $\mathrm{H}_{0}$ : there is a unit root for the series, $\mathrm{H}_{\mathrm{a}}$ : There is no unit root for the series. The series is stationary, As the computed p-value is lower than the significance level alpha=0.05, one should reject the null hypothesis $\mathrm{H}_{0}$, and accept the alternative hypothesis $\mathrm{H}_{\mathrm{a}}$.

${ }^{\$}$ SNT = stationery series with no trend, NSDT = Non stationary decreasing in trend series.

The partial autocorrelation of an AR $(p)$ process is zero at lag $p+1$ and greater. If the sample autocorrelation plot indicates that an AR model may be appropriate, then the sample partial autocorrelation plot is examined to identify the order. We look for the point on the plot where the partial autocorrelations essentially become zero. Placing a 95 per cent confidence interval for statistical significance is helpful for this purpose.

The plot of PACF for rainfall, runoff, temperature and evaporation for Savitri basin are presented in Figure 7, 8, 9 and 10, respectively. Examine the partial autocorrelation function which is showed in the figures that, there is a need to apply a simple subtraction. After subtracting the simple necessity of applying a seasonal differencing is required. This partial autocorrelation plot shows clear statistical significance for lags 1 and 2 (lag 0 is always 1). The next few lags are at the borderline of statistical significance. If the autocorrelation plot indicates that an AR model is appropriate, we could start building an AR (2) model. This might compare this with an AR (3) model. The PAC function coefficient of different parameter is presented in Table 1. It is observed form the Figure 7-10 that, the PACF have high values at certain lags. This indicates the need of differencing for the data sequence.

\section{Cross Correlation Function (CCF)}

Cross-correlation is an analysis used to determine if there is a relationship exists between two time series. In this case, runoff and rainfall time lag is applied to one of them. This is also known as a sliding predictor or sliding inner-product. It is commonly used for searching a long signal for a shorter known feature. It has applications in pattern recognition, single particle analysis, and averaging. The range of the cross correlated coefficients should be between -1 and 1 . The 
cross-correlation is then evaluated as a function of the spacing between the interval between data points ( $\delta t)$ using the pairs $\left[x\left(t_{\mathrm{i}}\right), y\left(t_{\mathrm{i}}+N \mathrm{\sigma} t\right)\right]$ for all integers $N$. Unfortunately, regularly sampled data are almost never found in hydrology. The essence of the cross correlation problems in hydrology deals with time series that are not evenly sampled. Moreover, the light curves are often limited in extent and are noisy. It is estimated for rainfall and runoff of Savitri basin on daily time steps with 7 days lag period presented in Figure 11. It is observed from the Figure 11 that, maximum cross correlation between rainfall and runoff of Savitri basin were exists at less lag i.e at one day, whereas it goes continuously deceasing with increase in the lag day up to 7 days. This indicates the prediction of runoff for lag of one to two days lag is more accurate then after accuracy goes on decreasing in case of Savitri basin and Kal river also for runoff prediction. The same results were interpreted and are significant for lags at 95 per cent level of confidence [18] (Demirel et al., 2012). Therefore, in the modelling of runoff by different hydrologic models such as ANN, FL ARIMA etc, one and two day lag rainfall was needs to be considered. Thus, it indicates positive response will be observed for one to two day in next step of estimation and not in reverses direction.

The trend in hydrologic data such as rainfall, runoff, evaporation and temperature was analysed by Mann Kendal test for 20 years (1990 to 2011) for Savitri basin. The Rainfall and runoff was observed no trends in data sets and temperature and evaporation showing decreasing trends over the time period for Savitri basin. The Dickey and Fuller seasonality test and KPSS seasonality test shows that, all data used for test for Savitri basin were stationary and no seasonal effects were observed except for evaporation and temperature. Auto correlation function with seasonal differencing (120 days) observed sinusoidal wave patter with changing season's effect on the ACF coefficient for Savitri basin. The PACF seasonal coefficient for hydrologic time series data gives the significance in development of hydrologic model and implies that need to have subtraction of one or two day for building of hydrologic models. The cross correlation between dependant and independent time series implied that, for accurate estimation of steam flow from rainfall data inputs of one or two days lag is sufficient for modelling of runoff by different hydrologic models i.e ANN, FL, ARIMA, SWAT etc. Then after efficiency of model may reduces and not performed better comparatively.

Application of Research: The procedure is adopted for deciding the inputs parameters to considers as inputs in hydrologic model for better estimates of hydrologic parameters such as rainfall, stream flow, temperature, evaporation etc.

\section{References}

Adeloye, A. J. and Montaseri M., 2002. Hydrological Sciences J. 47(5): 679692.

Brockwell P. J, and R. A.Davis. 2002. Springer, pp: 434

Demirel M. C., M J. Booij, and E. Kahya. 2012. J of Hydrologic Engineering. 262-271.

Dickey, D. A., and W. A. Fuller. 1979. Journal of the American Statistical Association. 74: 427-431

Donnelly-Makowecki, L. M. and Moore, R. D. 1999. J. Hydrology. 219: 136-152, doi:10.1016/S0022-1694(99)00056-6

Ferguson T. S., C Genest, and M Hallin. 2000. The Canadian Journal of Statistics. 28:587-604.

Fernando. A.K. and Jayawardena, A. W. 1994 $20^{\text {th }}$ WEDC Conference on Affordable 
Water Supply and Sanitation, Colombo, Sri Lanka, pp. 310-313

Hameed, T., Marino, M. A., Devries, J. J. and Tracy, J. C. 1997. J. of Hydrologic Engineering, ASCE, 2(4): 157- 160

Helsel, R.D. and Hirsch, R.M. 1988. Water Resources Bull. 24(1) 201-204.

Janacek G., and L Swift. 1993. Ellis Horwood. New York. USA.

Karlsson I. B., T. O. Sonnenborg, K. H. Jensen, and J. C. Refsgaard, 2014. Hydrol. Earth Syst. Sci., 18: 595-610

Kwiatkowski, D., P. C. B. Phillips, P. Schmidt, Y. Shin. 1992: Journal of Econometrics, 54, pp. 159-178, NorthHolland.

Machiwal Deepesh and Jha M K. 2006. J.
Hydrol. Hydromech. 5(3): 237-257

Mohammad Kamruzzaman, Md Sumon Shahriar and Simon Beecham. 2014. Water, 6: 3528-3544

Refsgaard, J. C. and Knudsen, J. 1996. Water Resour. Res. 32: 2189-2202, doi:10.1029/96WR00896

Salas J. D., 1993. In: D. R. Maidment (editorin-chief), Handbook of Hydrology, McGraw-Hill, Inc., USA, pp. 19.119.72 .

Seibert, J.: 2003. Hydrol. 34:477-492

Syczewska Ewa Marta. 1997. Department of Applied Econometrics Working Papers: http://www.sgh.waw.pl/instytuty/zes/wp I.1-20.

\section{How to cite this article:}

Gharde, K.D., M.B. Nagdeve and Bisen, Y. 2019. Temporal Trend Analysis of Climatic Parameters of Savitri Basin. Int.J.Curr.Microbiol.App.Sci. 8(08): 1313-1326. doi: https://doi.org/10.20546/ijcmas.2019.808.155 